\title{
Schizophrenia: A Disease of Heteromodal Association Cortex?
}

Godfrey D. Pearlson, M.A., M.B., B.S., Richard G. Petty, M.Sc., M.D., M.R.C.Psych., Christopher A. Ross, M.D., Ph.D., and Allen Y. Tien, M.D.

There is considerable evidence of disturbances of multiple brain areas in schizophrenia. The clinical features and findings from pathologic and neuro-imaging studies suggest primary involvement of a system of parallel distributed networks within the neocortex-the phylogenetically recent heteromodal association cortex (HASC). There is evidence that HASC is a family of higher-order parallel distributed networks of circuits, mediating complex representationally guided behaviors. We argue that HASC regions are especially involved in schizophrenia. Lesions of HASC in the disease are likely to be neurodevelopmental in origin (as evidenced by such examples as reversed planum temporale asymmetry) which have been identified by magnetic resonance imaging as. specific regions of disproportionately reduced local gray matter volumes, and by neuropathologic examination as cellular migration disruptions. We believe the hypothesis of preferential heteromodal cortical abnormalities has heuristic value, and briefly indicate how it opens new avenues for investigating this debilitating condition.

[Neuropsychopharmacology 14:1-17, 1996]
KEY WORDS: Schizophrenia, Cerebral neocortex, Heteromodal association cortex

Structural and functional brain studies in schizophrenia have evolved rapidly from a stage at which it was unknown which - if any-regions were involved, to the demonstration that multiple regions of the brain are affected (Weinberger 1990; Buchsbaum 1990; Gur and Pearlson 1993; Andreasen et al. 1986; Breier et al. 1992; Andreasen et al. 1988; Berman and Weinberger 1990). There is a need for clear hypotheses to understand and organize these observations, and for means to test the competing explanations. The nature of the abnormalities in vivo is not uniform: structural studies have

From the Division of Psychiatric Neuro-Imaging (GDP, RGP), Department of Psychiatry (GDP, RGP, CAR, AYT), Department of Neuroscience (CAR), Department of Mental Hygiene (GDP, AYT), Johns Hopkins University, Baltimore, Maryland

Address correspondence to: Godfrey Pearlson, Director, Division of Psychiatric Neuro-Imaging, Johns Hopkins Hospital, Meyer 3-166, $600 \mathrm{~N}$. Wolfe Street, Baltimore, MD 21287-7362.

Received February 8, 1994; revised February 21, 1995; accepted March 31, 1995. shown both increases and decreases in the volumes of different structures (e.g., Barta et al. 1990; Jernigan et al. 1991.) and functionally several areas of hyper- or hypometabolism or bloodflow are reported (e.g., Berman and Weinberger 1990; Buchsbaum et al. 1992; Cleghorn et al. 1989; Early et al. 1989, Gur et al. 1987; Lewis et al. 1992; Liddle et al. 1992; Musalek et al. 1989). These variable findings have led some to suggest that they may be entirely nonspecific. Although it is unknown whether all the clinical syndromes of schizophrenia represent a single disease entity, we believe that there is now adequate evidence to localize the primary lesions responsible for the classic clinical features of schizophrenia to a defined brain system, and that the brain changes primarily occur in HASC and only secondarily in other areas.

We suggest, based on available data, a testable, if preliminary hypothesis that schizophrenia represents the clinical manifestations of a group of disorders in which disruption of heteromodal association cortical (HASC) networks is a central event. Because we advocate a specific hypothesis, we emphasize supportive evi- 
dence and mention discordant studies more briefly. There are limitations in current knowledge, and many aspects of human cerebral connectivity are unexplored.

Our hypothesis of predominant heteromodal association cortical involvement in schizophrenia derives from three major sets of evidence:

1. Human and nonhuman primate studies indicate heteromodal cortical regions are an evolutionarily recent family of interconnected higher-order neural circuits, mediating complex cognitive tasks, such as working memory, language, and aspects of focused attention. Some of these regions show striking lateral asymmetries. Heteromodal cortical regions undergo significant myelination and reorganization of synaptic connections during adolescence and early adult life, later than most other brain regions, and at a time when the incidence of schizophrenia rises sharply.

2. Recent neuropsychologic studies indicate that in addition to hallucinations and delusions, schizophrenic patients have cognitive deficits, especially for functions subserved by heteromodal cortex.

3 . The neocortical regions implicated in many neuropathologic, pathophysiologic, neuropsychologic, and neuro-imaging studies of schizophrenic patients are predominantly HASC regions. Finally, we summarize our own magnetic resonance imaging (MRI) observations suggesting that these regions are preferentially affected in schizophrenia.

\section{HETEROMODAL CORTEX AND SCHIZOPHRENIA: HISTORY}

The idea that schizophrenia represents a disease of the cerebral neocortex is not new. Alzheimer (1913) reported pathologic changes in cerebral cortex, although these were not replicated by subsequent researchers. Southard (1915) was the first to refer to association cortex as particularly involved in the disorder. A psychiatrist who carried out many early neuropathologic studies in schizophrenia, Southard stated that "structural (visible or invisible) changes of a mild developmental nature lie at the bottom of the disease process ... very striking is the preference of these changes to occupy the association-centers of Flechsig. For this there is probably a good a priori reason in the structure, late evolutionary development, and consequent relatively high lability of these regions" (Southard 1915). Although contemporary confirmatory evidence for Southard's hypotheses was lacking, we argue that his ideas, especially concerning neocortical phylogenetic recency and lability, bear reexamination.

Anatomic studies of heteromodal cortical regions have a long history. In the previous quote, Southard referred to Flechsig, another neuropathologist and psychiatrist who had earlier postulated the existence of several "association centers" i.e., complex neocortical regions normally mediating higher-order cognitive tasks, such as cross-modal sensory association (Flechsig 1896). Flechsig's centers were based on cellular maps, and comprised portions of frontal, parietal, temporal, and possibly occipital, lobes. Flechsig believed these association areas constitute the neural substrate for higher cortical functions and "comprise centers of all the more complex associations" (Villiger 1931). Flechsig suggested that fibers in white matter regions adjacent to these association cortical areas are the last to myelinate during normal human development.

\section{ANATOMY OF HETEROMODAL CORTEX}

There are many conceptual schemes for subdividing the human cerebral cortex. One valuable approach is that adopted by Mesulam (1985), based on patterns of structural complexity and differentiation formed by regions with shared characteristics. This results in a classification of cortex into five types (see Table 1 and Figure 1), in which heteromodal isocortex is the highest order of association neocortex. Heteromodal cortex, by definition, receives data from multiple sensory modalities or transmits data to multiple secondary motor cortices.

Our own concept of heteromodal association cortex (HASC) (illustrated in Figure 1) is similar to that of Mesulam, but based on both structural and functional considerations. Because the function of many prefrontal regions remains to be fully clarified, we have been conservative in inclusion of frontal neocortex, and thus omit some regions included by Mesulam. GoldmanRakic and her collaborators, (Goldman-Rakic 1987, 1988, 1990, 1991; Selemon and Goldman-Rakic 1988), using nonhuman primates, have contributed signifcantly to elucidating the anatomy and function of heteromodal association cortical regions, especially DLPFC with its extensive interconnections with other HASC regions.

As shown in Figure 1, major component areas of HASC include: (1) the dorsolateral prefrontal cortex (DLPFC), including human Brodmann areas 9 and 46 (Chavis and Pandya 1976; Barbas and Mesulam 1981; Jones and Powell 1970; Pandya and Kuypers 1969; Kojima 1980), Broca's motor speech region subsuming parts of Brodmann areas 44 (premotor), 45, and portions of 6 and 47 around the lower frontal convolution (Geschwind 1965, 1972; Galaburda 1980; Mesulam 1985); (2) auditory association portions of the superior temporal gyrus (STG), (Mesulam 1985) including part of Brodman areas 22, for example, planum temporale (which includes much of Wernicke's area) (Geschwind and Levitsky 1968); and (3) the inferior parietal lobule 
Table 1. Functional Subdivision of the Cerebral Cortex, Based on Mesulam's Classification (1985)

\begin{tabular}{|c|c|}
\hline Subdivision & Examples \\
\hline Limbic subcortex & Amygdala \\
\hline Allocortex & $\begin{array}{l}\text { Hippocampus } \\
\text { Piriform cortex }\end{array}$ \\
\hline Paralimbic cortex & $\begin{array}{l}\text { Parahippocampal gyrus } \\
\text { Entorhinal cortex } \\
\text { Orbitofrontal cortex } \\
\text { Anterior insula } \\
\text { Cingulate cortex }\end{array}$ \\
\hline Idiotypic cortex & $\begin{array}{l}\text { Primary sensory cortex } \\
\text { Primary auditory area (Heschl's gyrus) } \\
\text { Primary visual area } \\
\text { Primary motor cortex }\end{array}$ \\
\hline Isocortex & $\begin{array}{l}\text { Modality-specific association cortex, e.g., auditory association } \\
\text { cortex; visual association cortex }\end{array}$ \\
\hline Heteromodal cortex & $\begin{array}{l}\text { Dorsolateral prefrontal cortex (Brodmann areas } 9 \text { and } 46 \text { ), } \\
\text { Broca's area (including parts of Brodman areas } 45,44,6 \\
\text { and 47), portions of superior temporal gyrus, including } \\
\text { planum temporale (Brodmann area } 22 \text { ), and inferior } \\
\text { parietal lobule (Brodmann areas } 39 \text { and } 40 \text { ) }\end{array}$ \\
\hline
\end{tabular}

(IPL) Brodmann areas 39 and 40 (Bruce 1981; Hyvarinen 1981; Mesulam 1977; Selzer and Pandya 1978, 1984), which latter consists of the supramarginal and angular gyri.

Major features of heteromodal association neocortical regions are as follows: (1) characterization as an interconnected family of higher-order neural circuits comprising parallel distributed neocortical networks (Selemon and Goldman-Rakic 1988); (2) HASC regions are innervated by discrete regions of the thalamus, most especially, the medial dorsal nucleus and pulvinar (Trojanowski and Jacobson 1976; Jacobson and Trojanowski 1975; Guillery 1959; Morecraft et al. 1992; Schmah-

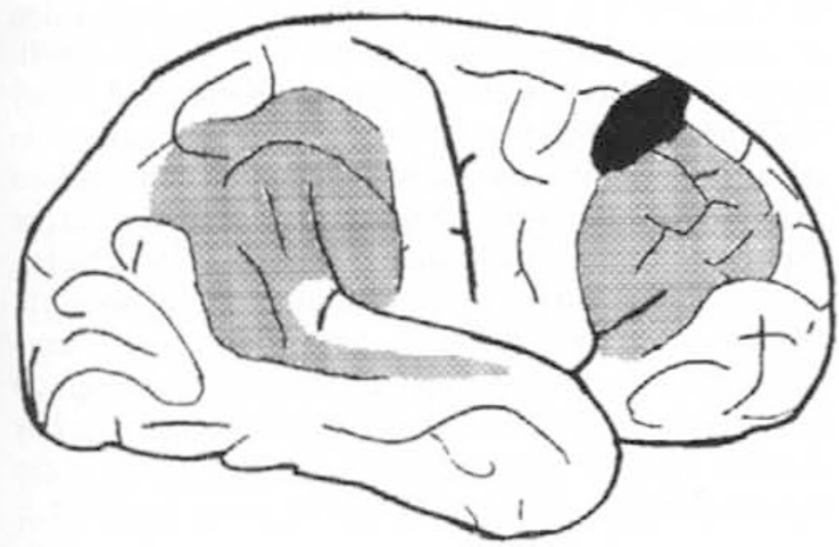

Figure 1. Conceptual map of human cortex modified from that of Mesulam (1985) showing shading of heteromodal association cortical areas. DLPFC is anterior, and IPL posterior, with STG proceeding horizontally from it. mann et al. 1990; Yeterian and Pandya 1991; Barbas et al. 1991); (3) normally highly laterally asymmetric in nature (Galaburda 1980; Galaburda and Sanides 1980; Eidelberg and Galaburda 1984); (4) phylogenetic recency (Osman Hill 1972; Jerison 1973); (5) ontogenetic recency (Sarnat and Netsky 1981): HASC circuits myelinate and prune late (adolescence or beyond) (Benes 1989; Feinberg 1992); (6) mediation of higher-order multimodal cognitive tasks (e.g., language, focused attention, working memory) (Goldman-Rakic 1990; Mesulam 1990); (7) consist of anterior (motor) and posterior (sensory) components (Goldman-Rakic 1990).

Some functions are summarized in Table 2. Damage to portions of the heteromodal cortex results in behavioral and neuropsychologic deficits that are nonmodality-specific. By contrast, in unimodal association cortex (Mesulam 1977, 1981, 1985) neurons respond only to one type of sensory input from one primary sensory cortex, and damage produces deficits only in that modality. Each region of heteromodal neocortex shows evidence of direct multimodal convergence (Benevento 1977; Bignall and Imbert 1969) receiving inputs from multiple unimodal areas and from other heteromodal association areas, including its pair in the opposite hemisphere (Barbas and Mesulam 1981; Mesulam and Mufson 1984; Mesulam et al. 1977; Rosene and VanHoesen 1977).

Heteromodal areas also have rich and extensive interconnections with specific areas within the limbic system, especially to paralimbic regions such as cingulate cortex, parahippocampal gyrus, and caudal orbitofrontal cortex (Mesulam 1985; Barbas and Mesulam 1981; 
Table 2. Heteromodal Association Cortical Regions

\begin{tabular}{|c|c|c|c|}
\hline Location & $\begin{array}{l}\text { Neuropsychology and } \\
\text { Physiology }\end{array}$ & Neurology & Connectivity \\
\hline $\begin{array}{l}\text { Dorsolateral prefrontal } \\
\text { Broadmann areas } 9+ \\
46 \text { (Area FD-delta of } \\
\text { Von-Economo) } \\
\text { (Mesulam 1985; } \\
\text { Goldman-Rakic 1990). }\end{array}$ & $\begin{array}{l}\text { Executive and integrative tasks, } \\
\text { including working memory; } \\
\text { socialization; motivation; } \\
\text { complex problem-solving; } \\
\text { verbal fluency; spatially } \\
\text { guided movement (Goldman- } \\
\text { Rakic 1990) }\end{array}$ & $\begin{array}{l}\text { Immediately adjacent to areas } \\
\text { controlling saccadic eye } \\
\text { movements; "motor inte- } \\
\text { gration" (Barbas and } \\
\text { Mesulam 1981; Goldman- } \\
\text { Rakic 1990) }\end{array}$ & $\begin{array}{l}\text { Inferior parietal, basal } \\
\text { ganglia, temporo- } \\
\text { limbic, anterior cin- } \\
\text { gulate (Selemon } \\
\text { and Goldman-Rakic } \\
\text { 1988) }\end{array}$ \\
\hline $\begin{array}{l}\text { Broca's area } \\
\text { Brodmann areas 44, 45, } \\
\text { 6, } 47 \text { (Mesulam 1985; } \\
\text { Geschwind 1972) }\end{array}$ & $\begin{array}{l}\text { Motor speech (Benson and } \\
\text { Geschwind 1985) }\end{array}$ & $\begin{array}{l}\text { Motor and premotor regions } \\
\text { (Mesulam 1985) }\end{array}$ & $\begin{array}{l}\text { STG, IPL, DLPFC, } \\
\text { (Benson and } \\
\text { Geschwind 1985) }\end{array}$ \\
\hline $\begin{array}{l}\text { Inferior parietal } \\
\text { Brodmann areas } 39+ \\
40 \text { (Mesulam 1985; } \\
\text { Selzer and Pandya 1978) }\end{array}$ & $\begin{array}{c}\text { "Focusing and execution" of } \\
\text { attention (Posner 1988) }\end{array}$ & $\begin{array}{l}\text { Oculomotor smooth pursuit } \\
\text { (Anderson 1990); "Supra- } \\
\text { modal" and "sensory-motor } \\
\text { integration" (Mesulam 1985) }\end{array}$ & $\begin{array}{l}\text { DLPFC, limbic cortex } \\
\text { (Selemon and } \\
\text { Goldman-Rakic } \\
\text { 1988; Selzer and } \\
\text { Pandya 1978) }\end{array}$ \\
\hline $\begin{array}{l}\text { Superior temporal } \\
\text { Brodmann area } 22 \\
\text { (Mesulam 1985; } \\
\text { Geschwind 1972) }\end{array}$ & $\begin{array}{l}\text { Auditory + semantic pro- } \\
\text { cessing; receptive language } \\
\text { (Benson and Geschwind } \\
\text { 1985); source for P } 300 \\
\text { evoked potential (Knight } \\
\text { 1987) }\end{array}$ & $\begin{array}{l}\text { "Sensory integration," } \\
\text { language (Benson and } \\
\text { Geschwind 1985) }\end{array}$ & $\begin{array}{l}\text { Limbic regions, IPL, } \\
\text { DLPFC (Geschwind } \\
\text { and Levitsky 1968) }\end{array}$ \\
\hline
\end{tabular}

Jones and Powell 1970; Mesulam 1977; Pandya and Kuypers 1969).

HASC comprises densely interconnected regions, as shown for example, by Selemon and Goldman-Rakic's (1988), double-label experiments in the rhesus monkey. A very large number of cortical and subcortical areas receive common efferent projections from area PS (the rhesus analogue of DLPFC in area 46), and area IPS (the rhesus analogue of IPL in area 7) (see Figure 2) (Mesulam et al. 1977; Pandya et al. 1981; Seltzer and Pandya 1978).

\section{Asymmetry of Neocortical Regions}

Structural and functional cerebral cortical lateral asymmetry, although not limited to humans (Sarnat and Netsky 1981; Nottebohm 1976), is most striking in the human brain, and primarily confined to heteromodal regions. Some asymmetrical language regions, such as Broca's speech area (the pars opercularis and triangularis of the inferior frontal gyrus), and Wernicke's area (which overlaps in part the dominant planum temporale) may be unique to humans.

Heteromodal association cortical regions are normally the most asymmetrical in the human brain. Cytoarchitectonic asymmetries of a clear-cut nature have been reported in normal subjects for the inferior parietal lobule (Eidelberg and Galaburda 1984), for planum temporale (Galaburda and Sanides 1980), and for Broca's area (Galaburda 1980). Some of these asymmetries are evident during fetal development (Chi 1977). To our knowledge the dorsal lateral prefrontal cortex has not been studied in a similar manner. The planum temporale is the most straightforward region to define in terms of gross anatomy, and here clear anatomic asymmetries have been demonstrated (Geshwind 1968). Most recently, MRI studies have been used to demonstrate asymmetries in some HASC regions, most convincingly for the planum temporale (e.g., Steinmetz et al. 1989; Kulynych et al. 1993; Barta et al., in press).

\section{Phylogenetic Recency}

The cortical areas devoted to association have increased during phylogeny relative to other areas of brain (Osman Hill 1972, p. 60). In humans this increase is often presumed to be primarily frontal (e.g., Hofer 1969). However, others (Kluver 1951; vonBonin and Bailey 1947; Jerison 1973) emphasize that "corticalization" in advanced primates consists in expansion of the regions of temporal lobe "as much or more ... as it does in the expansion of prefrontal areas" (Jerison 1973). The latter also states that the emphasis on temporal neocortical expansion was "mainly to correct or, at least, ameliorate the effects of the almost gratuitous assumption among neurologists and neuropsychologists of a few decades ago that the frontal lobes were the only areas in which higher 'psychic' functions were localized."

\section{Ontogenetic Recency}

In cerebral cortex, the neocortical neurons are the last to migrate ontogenetically, just as they are the most recent to arise phylogenetically (Sarnat and Netsky 1981; 


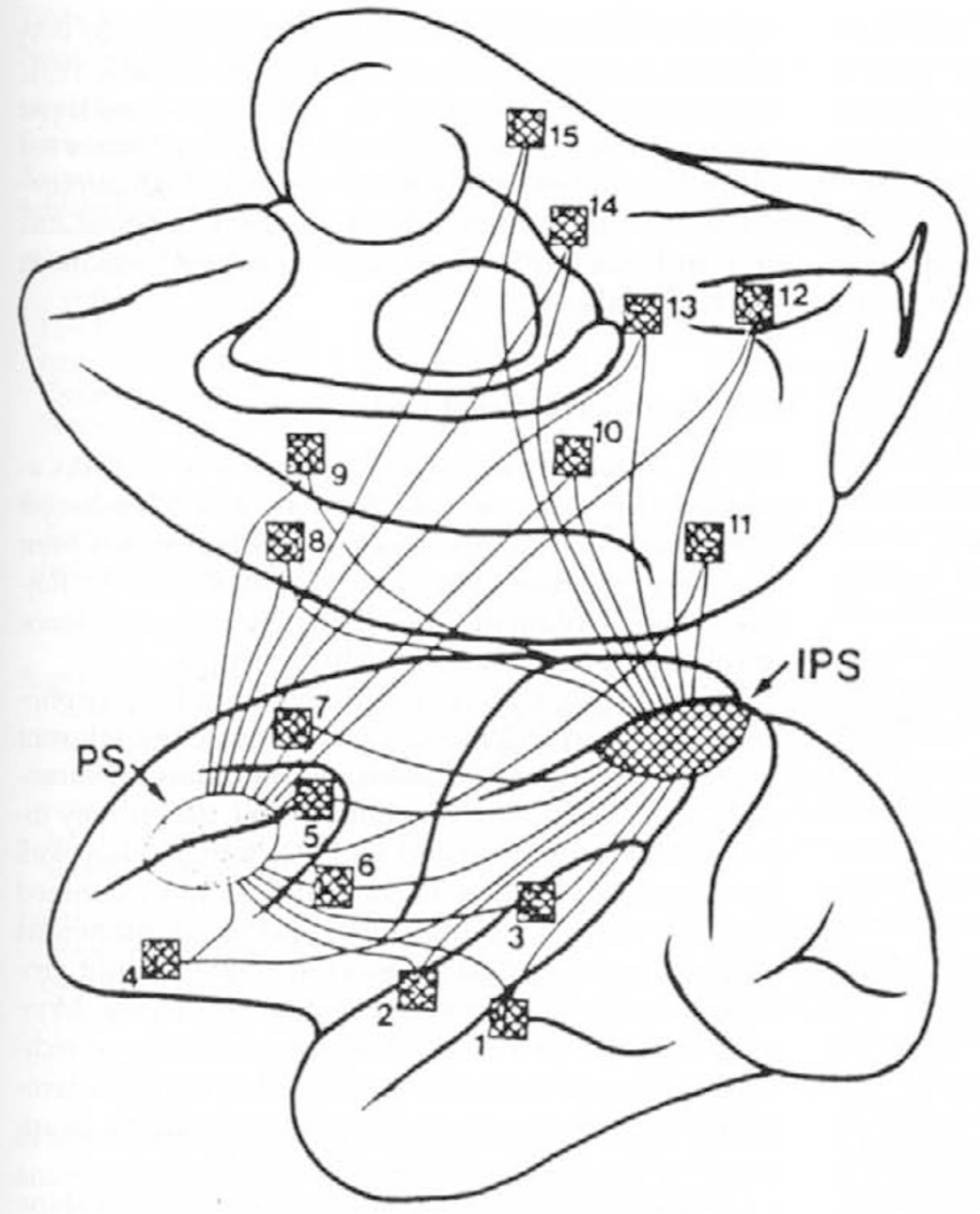

Figure 2. Circuit demonstrated in nonhuman primates by double anterograde tracing technique following tracer placement in prefrontal $(\mathrm{PS}=$ area 46$)$ and posterior parietal (IPS = area 7) cortices described in Selemon and Goldman-Rakic (1988). These two centers, which correspond to human DLPFC and IPL, project to multiple common targets including superior temporal gyrus and parahippocampal gyrus (labeled 15). Reprinted from GoldmanRakic (1990).
Berry and Rogers 1965; Sidman and Angevine 1962; Angevine and Sidman 1961, 1962). HASC regions undergo myelination (Benes 1989) and pruning (Feinberg 1982; Feinberg et al. 1990; Feinberg 1992) through late adolescence, a time when there is an increasing incidence of schizophrenia.

\section{FUNCTION}

We now know that these heteromodal association areas of the brain form an integrated system or family of circuits of critical importance in coordinating many sensory, motor, and behavioral activities and integrating them with drive and mood (e.g., Mesulam et al. 1977; Lynch 1980). As Flechsig (1896) hypothesized, they mediate complex cognitive tasks such as attention, planning, language, and working memory, using knowledge of prior events to guide current behavior (GoldmanRakic 1990; Mesulam 1990). Thus, regions of sensory heteromodal cortex do not receive sensory information directly, but coordinate complex preprocessed data from more than one sensory sphere. For instance, the recognition that a cube held in the hand is the same object seen in a picture, or the simultaneous processing sensations of the sight, smell, and taste of food are mediated within heteromodal association areas. Other heteromodal association areas integrate sensory and motor activities. For example, some cells within these regions increase their firing in response to sensory input, but only in phase with motor output (Kojima et al. 1981; Kubota et al. 1980), and in response to motivational relevance (Lynch 1980) or behavioral cues (Kojima 1980). Heteromodal areas integrate information from both extrapersonal space and the internal milieu (Mesulam 1985; Kievit and Kuypers 1975), and can generate and access internal sensory and motor representations of the external world, and use this information to guide attentional and perceptual responses (Goldman-Rakic 1990; Drooglever-Fortuyn 1979; Mesulam 1981).

HASC circuits can be considered to have more anterior "motor" or output regions, and more posterior "sensory" or receptive portions. For example, in the rhesus monkey the HASC circuit linking (anterior) area 46 in prefrontal cortex (corresponding to human dorsolateral prefrontal cortex) and (posterior) area 7a in inferior parietal cortex mediates spatial delayed response tasks (Goldman-Rakic 1990). In humans, other exam- 
ples are those of Broca's (anterior, motor) and Wernicke's (posterior, sensory) speech/language regions (Geschwind 1965). Heteromodal regions thus "provide a neural template for intermodal associations necessary for many cognitive processes, especially language" (Mesulam 1985).

These neural networks consist of interconnected regions allowing parallel distributed processing, and map complex behaviors "at the level of multifocal neural systems rather than specific anatomical sites" (Mesulam 1990). Thus, Goldman-Rakic has shown that the nonhuman primate equivalents of DLPFC and IPL form a distinct, highly organized neural system, with multiple reciprocal interconnections to similar higher-order cortical regions such as STG. "These shared connections constitute part of an elaborate anatomical circuit which could mediate many aspects of spatial function, including spatial perception, attention, memory and spatially guided movement" (Seleman and GoldmanRakic 1988). Other aspects of the circuit mediate other, similarly complex cognitive functions. In the temporal lobe, connections to other HASC regions are most prominent in portions of the superior temporal sulcus, an area known to be connected to the above mentioned frontal and parietal regions from prior investigations (e.g., Seltzer and Pandya 1978, 1984). Although the area 46 to area 7 circuit mediating representationally guided spatial delayed response tasks is the paradigmatic and best-studied HASC neural circuit, HASC should be viewed as a family of such parallel distributed networks, each with its anterior/motor and posterior/sensory components. For example, immediately adjacent to area 46 in primate prefrontal cortex is area 12 . Together with its linked posterior cortical area, this circuit is responsible for feature-dependent, memory-mediated delayed response tasks. Parietal heteromodal areas contain a "multidimensional representational schema of the extrapersonal world" (Mesulam 1985). The example of language was cited previously, and there is increasing evidence that other members of this family of parallel distributed polymodal cortical networks constitute the anatomic substrate of additional complex cognitive tasks.

\section{REGIONS OF HETEROMODAL ASSOCIATION CORTEX AND SCHIZOPHRENIA}

Schizophrenia involves subtle alterations in higher cognitive functions, such as those involving ability to change cognitive set, respond to social cues, and perform long-range planning. These functions are notable for their association with areas of heteromodal cortex, as described later.

Whereas some investigators have focused on the relevance to schizophrenia of particular components of heteromodal association cortex, most prominently dorsolateral prefrontal cortex (e.g., Goldman-Rakic 1991; Weinberger 1991; Mirsky et al. 1992), we extend these arguments by proposing prominent dysfunction of the entire distributed heteromodal network in schizophrenia, as summarized in Table 3 . We review below further evidence implicating individual HASC regions in schizophrenia.

\section{Dorsolateral Prefrontal Cortex}

DLPFC involvement in schizophrenia is well documented (for example, see Berman and Weinberger 1990). Neuropathologic study of this region has been relatively neglected, but careful recent studies by Rajkowska and Goldman-Rakic (1991) show clear evidence of cellular abnormalities in schizophrenia.

Convincing structural MRI evidence for morphologic change in DLPFC is scanty because the relevant region is very difficult to delineate specifically. The frontal lobe as a whole is functionally and structurally diverse (Mesulam 1985) and DLPFC changes may well be regionally selective. Earlier MRI studies examined large portions of frontal lobe, including numerous different regions (Andreasen et al. 1986) did not produce consistent or convincing evidence of change. More recently, Schlaepfer et al. (1994), using cortical peel techniques, showed more convincing reductions in heteromodal association cortical gray matter, including an approximation to dorsolateral prefrontal cortex.

SPECT regional cerebral blood flow studies show reduced $\mathrm{rCBF}$ when schizophrenic patients perform cognitive tasks mediated via circuits including this region, including the Wisconsin Card Sorting Test (Berman and Weinbergerr et al. 1990a,b; Rubin et al. 1991) and verbal fluency tasks (McGuire et al. 1993).

Cognitive deficits in functions normally subserved by dorsolateral prefrontal cortex in both humans (Goldman-Rakic 1991) and nonhuman primates (GoldmanRakic 1990) such as aspects of set shifting and working memory have been shown to be abnormal in schizophrenic patients (Park and Holzman 1992).

\section{Heteromodal Regions of Superior Temporal Gyrus}

The superior temporal gyrus contains both heteromodal association cortex and primary sensory cortex. The planum temporale, which is an HASC region, is in the posterior portion of the superior temporal gyrus and is a highly lateralized asymmetric speech region, whereas Hechl's gyrus, which is more anteriorly located, consists of primary auditory cortex (Mesulam 1985).

Gross neuropathologic involvement of STG was first remarked on by Southard (1915), but more recently temporal neocortical change has been shown at autopsy 
Table 3. Overview of HASC Dysfunction in Schizophrena and supportive neuropathologic and Neuro-Imaging Evidence

\begin{tabular}{|c|c|c|c|c|c|}
\hline $\begin{array}{l}\text { Hypothesized } \\
\text { Symptomatic } \\
\text { Association in } \\
\text { Schizophrenia }\end{array}$ & $\begin{array}{l}\text { Neuropathologic } \\
\text { Involvment in } \\
\text { Schizophrenia }\end{array}$ & $\begin{array}{l}\text { MRI Changes } \\
\text { in Schizophrenia }\end{array}$ & $\begin{array}{l}\text { Physiologic } \\
\text { or Neuropsych. } \\
\text { Deficits in } \\
\text { Schizophrenia }\end{array}$ & $\begin{array}{c}\text { SPECT } \\
\text { Changes in } \\
\text { Schizophrenia }\end{array}$ & $\begin{array}{l}\text { PET Changes } \\
\text { in } \\
\text { Schizophrenia }\end{array}$ \\
\hline $\begin{array}{l}\text { Dorsolateral prefrontal } \\
\text { cortex } \\
\text { Psychomotor poverty, } \\
\text { negative symptoms } \\
\text { (Berman and Wein- } \\
\text { berger 1990) }\end{array}$ & $\begin{array}{l}\text { Decreased cell density, } \\
\text { layer VI, prefrontal } \\
\text { cortex. No gliosis } \\
\text { (Rajkowska and } \\
\text { Goldman-Rakic, } \\
\text { in press) }\end{array}$ & $\begin{array}{l}\text { Reduced volume, } \\
\text { correlating with } \\
\text { negative symp- } \\
\text { toms (An- } \\
\text { dreasen 1986) }\end{array}$ & $\begin{array}{l}\text { Set shifting, } \\
\text { working } \\
\text { memory, and } \\
\text { verbal fluency } \\
\text { all impaired, } \\
\text { impaired } \\
\text { saccades }\end{array}$ & $\begin{array}{l}\text { Reduced flow } \\
\text { with WCST, } \\
\text { and verbal } \\
\text { fluency } \\
\text { (Berman } \\
\text { and Wein- } \\
\text { berger 1990) }\end{array}$ & $\begin{array}{l}\text { "Hypo- } \\
\text { frontality" }\end{array}$ \\
\hline $\begin{array}{l}\text { Broca's area } \\
\text { Auditory hallucina- } \\
\text { tions (McGuire 1993) }\end{array}$ & Unknown & Unknown & & $\begin{array}{l}\text { Increased } \\
\text { flow with } \\
\text { auditory } \\
\text { hallucina- } \\
\text { tions }\end{array}$ & \\
\hline $\begin{array}{l}\text { Superior temporal } \\
\text { cortex } \\
\text { "Reality distortion," } \\
\text { auditory hallucina- } \\
\text { tions, thought disor- } \\
\text { der (Barta 1990; } \\
\text { Shenton 1992) }\end{array}$ & $\begin{array}{l}\text { Disrupted sulcal/ } \\
\text { gyral morphology } \\
\text { Jakob and Beck- } \\
\text { man } 1989\end{array}$ & $\begin{array}{l}\text { Reduced volume } \\
\text { correlating with } \\
\text { hallucinations, } \\
\text { thought dis- } \\
\text { order, reversed } \\
\text { PT asymmetry }\end{array}$ & $\begin{array}{l}\text { Reduced P300 } \\
\text { amplitude }\end{array}$ & $\begin{array}{l}\text { Flow changes } \\
\text { with audi- } \\
\text { tory hallu- } \\
\text { cinations }\end{array}$ & $\begin{array}{l}\text { Decreased } \\
\text { bloodflow }\end{array}$ \\
\hline $\begin{array}{l}\text { Inferior parietal cortex } \\
\text { "Reality distortion," } \\
\text { negative symptoms } \\
\text { (Tamminga 1992) }\end{array}$ & Unknown & $\begin{array}{l}\text { Reduced volume, } \\
\text { reversed asym- } \\
\text { metry (McGil- } \\
\text { christ 1993) }\end{array}$ & $\begin{array}{l}\text { Impaired atten- } \\
\text { tional focus. } \\
\text { Abnormal } \\
\text { smooth pursuit }\end{array}$ & & $\begin{array}{l}\text { Decreased } \\
\text { bloodflow }\end{array}$ \\
\hline
\end{tabular}

as sulcalgyral disruption by Jakob and Beckman (1989) and shape disturbances on MRI (Casanova et al. 1990).

Volume reduction in the more anterior STG on MRI is associated with positive schizophrenic symptoms, particularly hallucinations (Barta et al. 1990; Flaum et al. 1992), whereas reduction in the more posterior region is associated with thought disorder (Shenton et al. 1992; Menon et al., 1995).

Functional imaging SPECT studies have shown increased flow associated with auditory hallucinations in the left superior temporal gyrus (Suzuki et al. 1993) and failure to activate perisylvian flow with semantic memory tasks in schizophrenic patients (Wood 1990).

Electrical stimulation of the STG in conscious humans elicited apparent auditory hallucinations (Penfield and Perot 1963). Although Gloor (1990) emphasized the role of medial temporal structures in this regard, Bancaud et al. (1994) have shown convincingly that superior temporal gyrus, amygdala, and anterior hippocampus constitute portions of a circuit forming a substrate for psychoticlike experiences and reemphasized the role of the STG (as has other recent work in such symptoms occurring in temporal lobe epilepsy, Jibiki et al. 1993). Furthermore, the P-300 evoked potential (elicited by novel auditory stimuli) is generated in the locale of STG (Knight et al. 1987). In many studies the auditory P-300 amplitude is reduced in patients with schizophrenia, and this is associated with reductions in the volume of gray matter in the posterior STG (McCarley 1993). Magnetoencephalographic changes in schizophrenia are consistent with abnormalities within the STG region (Reite et al. 1989), and SPECT bloodflow changes in STG parallel the occurrence of auditory hallucinations (Suzuki et al. 1993).

Cognitive deficits such as impaired selective attention (Mirsky et al. 1992) seem to point toward specific abnormal interactions between inferior parietal lobule and superior temporal regions, a good example of disturbed network functions.

\section{Inferior Parietal Lobule}

Concentration upon frontal and temporal lobe involvement in schizophrenia has led to a recent relative neglect of the parietal lobes, although there is much evidence of involvement of these regions. Mesulam and Geschwind (1983) suggested that the parietal lobes might be impaired in schizophrenia. No clear neuropathologic studies have been carried out.

Few MRI studies have focused on this region. Schlaepfer et al. (1994) showed reduced gray matter volume in this heteromodal area, and a preliminary study from McGilchrist et al. (1993) has shown strikingly reduced gray matter volumes in the inferior parietal lob- 
ule. The latter study used high resolution $1.5 \mathrm{~mm}$ SPGR MRI images, with 3-D volume rendering, to define the IPL from its surface sulcalgyral landmarks and then to further measure its gray and white matter from the original 2-D coronal slices. IPL was reliably defined blindly in 10 DSM-III-R male schizophrenics, and an equal number of screened normal controls, individually matched to patients on age, sex, race, and parental SES. IPL gray volume subsequently defined by thresholding was significantly smaller (by $26 \%$ ) in schizophrenics on the right side, with similar but lesser $(10.5 \%)$ gray volume reductions on the left side. No white matter differences were seen on either side, and total cerebral gray matter reductions in schizophrenics were of a smaller degree than those noted in IPL, comparable with values noted by us previously (Schlaepfer et al. 1994),

Several authors (Zec and Weinberger 1986; Posner et al. 1988; Cleghorn et al. 1989) more recently reviewed the functional imaging evidence for parietal association cortex involvement in schizophrenia. Reduced inferior parietal glucose metabolism is found in both treated and untreated schizophrenic patients (Cleghorn et al. 1989; Liddle et al. 1992; Wiesel et al. 1987; Kishimoto et al. 1987, Tamminga 1992). As Cleghorn (1989) points out, right parietal lobe function is important in maintaining attention to sensory stimuli, as well as in affective recognition, behaviors commonly disturbed in patients with schizophrenia. Tamminga et al. (1992) found frontal and parietal cortical glucose hypometabolism to be associated with the deficit subgroup of schizophrenics.

Smooth pursuit eye movement abnormalities of the type reported in schizophrenic patients show some localization to the inferior parietal lobule (e.g., Anderson et al. 1990). Deficit schizophrenics have more eye movement abnormalities than nondeficit patients (Thaker et al. 1989). Other animal studies (Andersen et al. 1990) also stress the normal role of parietal, as well as frontal cortex in maintaining oculomotor functions often found to be disturbed in schizophrenia.

Petersen et al. (1989) have discussed the role of parietal cortex lesions in impairment of visual spatial attention in humans. Similar attentional deficits have now been shown in schizophrenic patients by several groups (e.g., Posner et al. 1988). Cleghorn, for example (Cleghorn et al. 1989, 1989), stressed the role of the parietal lobes in attention and "to the significance of events and objects in the external environment," whereas Borod et al. (1986) found both schizophrenic patients and those with right hemisphere lesions to be impaired in voice and face recognition, and emotional expression in vocalizations and facial expressions. The IPL is involved in the maintenance of selective attention (Heilman et al. 1983; Mirsky et al. 1991), which is frequently impaired in schizophrenia (Petersen et al. 1989), implying abnormalities in a network including STG. Parietal lobe neurologic signs are observed in schizophrenia (Manschreck and Ames 1984), and recognition of faces - a parietal lobe function-may be impaired in acute schizophrenia (Harrington et al. 1989). It has also been suggested that lack of insight, which so frequently bedevils the management of schizophrenia, may be associated with parietal lobe dysfunction (David 1990).

\section{Disturbances in Neocortical Asymmetry}

Lateral asymmetry of the cerebral cortex is a relatively late development in primate evolution (Deuel and Dunlop 1980) and is linked with both handedness and the human capacity for speech and communication (Geschwind and Levitsky 1968). As noted earlier, the most marked human brain asymmetries are in HASC areas. Southard 80 years ago suggested that the neuropathology of schizophrenia was related to changes in the left hemisphere (Southard 1915). Benson and Geschwind (1968) hypothesized that specific neuropsychiatric disorders might be related to abnormal cerebral dominance. Flor-Henry (1969) proposed that disturbances in cerebral lateralization were of pathophysiologic importance in schizophrenia. Crow $(1990 a, b)$ hypothesized a crucial role in schizophrenia for one specific highly lateralized site in the heteromodal association cortical loop, the planum temporale. He suggested that this abnormality results from disturbances in the expression of a hypothesized gene, which controls normal cerebral asymmetry. Crow's evidence includes reports of left lateralized abnormalities in the brains of patients with schizophrenia (e.g., Bogerts et al. 1990; Falkai et al 1992), male/female differences in both cerebral lateralization and disease expression (Lewine 1981), and the usually highly asymmetric nature of the planum temporale, which lies in the most posterior portion of the superior temporal gyrus and contains Wernicke's area (Geschwind and Levitsky 1968). Petrides and Pandya (1984) elucidated projections from the monkey homologue of this locale to specific matching regions within frontal lobe association areas.

On following up earlier, more indirect neuropathologic evidence (e.g., Falkai 1992), Steinmetz recently suggested practical ways of directly measuring the planum temporale area from MRI scans in living humans (Steinmetz et al. 1990), making Crow's conjecture concerning the planum temporale directly testable. We (Petty et al. 1995) and others (Rossi et al. 1994) have strong evidence for abnormal PT lateralization in schizophrenia. In recent work from Petty et al. (1995), high-resolution MRI scans were obtained in 14 strongly right-handed schizophrenic patients and 14 healthy comparison subjects individually matched for age, sex, handedness, race, and parental socioeconomic status. The surface area of the PT was measured using MRI reconstruction techniques employing tessellation to rep. 
resent the folded surface of the planum. There was reversal of the normal, ( $\mathrm{L}>\mathrm{R}), \mathrm{PT}$ surface area asymmetry in 13 of the schizophrenic patients but in only two of the comparison subjects. Severity of thought disorder was correlated with extent of asymmetry. By contrast, Heschl's gyrus (primary sensory cortex), an anatomically contiguous nonheteromodal cortical comparison region, showed no difference between the left and right sides in either group. This work is a clear demonstration of a reversal of expected asymmetry in the brains of right-handed schizophrenic patients. As the PT asymmetry is normally apparent by the 30th week of gestation, the nature of this abnormality strongly suggests a neurodevelopmental basis. The study of McGilchrist et al. (1993) also showed deviant asymmetries of the IPL in schizophrenia.

Functional changes in schizophrenia have also been noted in other asymmetrical HASC regions by others, e.g., Wood and Flowers (1990), Suzuki et al. (1993), and McGuire et al. (1994), in perisylvian cortex, Wernicke's area and Broca's area respectively. Thus, we find Crow's arguments for disturbed lateralization, and especially for involvement of planum temporale in schizophrenia persuasive, but see disturbed planum asymmetry as only one of several examples of HASC pathology associated with schizophrenia.

\section{SPECIFICITY OF CHANGES WITHIN NEOCORTEX IN SCHIZOPHRENIA}

One major issue in schizophrenia is identifying the regions most severely affected. Because the neuropathology is subtle, pathologic studies of individual brain regions are unwieldy, and it is difficult to choose an ideal area of the brain to study. Some of the conflicts in the neuropathologic literature are likely to be due to the fact that different investigators have selected different brain regions for study based on different hypotheses, and that until recently, relatively little work has been carried out on HASC regions. Although there is MRI and other evidence of relatively slight, generalized gray matter reductions in schizophrenia, comparatively little attempt has been made to test this hypothesis versus that of disproportionate regional neocortical loss.

We have argued here for specific, rather than generalized neocortical involvement in schizophrenia, a state of affairs that is feasible on embryologic grounds (Hanaway et al. 1968). In contrast to this hypothesis, generalized reductions in gray matter volume in schizophrenia have recently been reported from MRI studies (Zipursky 1992), raising the possibility of widespread and nonlocalized changes in cortical and subcortical gray matter. However, both our own and other recent (Zipursky 1992) gray/white segmentation studies show only slight $(2 \%$ to $5 \%)$ generalized reduction in cortical gray matter, considerably less than the degree of heteromodal decreases (e.g., Schlaepfer et al. 1994). The hypothesis that changes in the different cortical areas implicated in schizophrenia reflect a process predominantly involving HASC can be tested directly by establishing whether significantly disproportionate loss of cortical gray matter volume occurs within HASC areas. In a recent MRI study (Schlaepfer et al. 1994), total brain and regional gray matter volumes were calculated using a cortical circumferential profiling method, in 46 schizophrenic patients and 60 age- and sex-matched controls from MRIs. Disease specificity was examined by assessing 27 patients with bipolar disorder. Approximations to dorsolateral prefrontal, inferior parietal, and superior temporal cortex were selected as regions of interest for heteromodal association cortex. Occipital, sensory-motor, and other regions were used as cortical control areas to test the hypothesis for regional specificity.

Gray matter volume was found to be reduced in schizophrenic patients in all three HASC index regions, even when covaried for overall brain volume, sex, and age. Bipolar patients did not exhibit similar heteromodal gray matter reduction. By contrast, control regions were not significantly different among the three groups. Global gray matter volume differences were not significant among groups after covarying for global brain volume (although both global brain volume and global gray matter volume were both modestly reduced in schizophrenics compared to controls). Comprehensive individual regional post-hoc analysis found gray matter differences between schizophrenics and comparison groups only in heteromodal regions. These findings support the theory of disproportionate reduction of heteromodal association cortex specific to schizophrenia.

\section{ALTERNATIVE EXPLANATIONS}

There have been many other attempts to synthesize experimental findings of the numerous brain changes documented in schizophrenia. These hypotheses have variously emphasized as primary to the disorder dysfunction of (1) the entire frontal lobe, (2) the limbic system, (3) the basal ganglia, or (4) the thalamus. We suggest below that several of these theories are correct in part, but that they represent single examples, special cases, or secondary effects of primary dysfunction in the HASC system.

\section{The Frontal Lobe}

There is an extensive literature using PET and SPECT implicating changes in frontal lobe glucose metabolism or bloodflow in schizophrenia [for review of "hypofrontality," see Pearlson (1991)]. Studies to date are con- 
strained by the structural and functional heterogeneity of the quite large brain regions assessed and the major problems inherent in defining these reliable and valid anatomic subregions of maximal relevance for analysis. Weinberger's group (e.g., Weinberger 1994; Berman and Weinberger 1990; Berman et al. 1992; Weinberger et al. 1992) has produced convincing evidence for defective function of the DLPFC in schizophrenia, by showing reduced regional cerebral blood flow $(\mathrm{rCBF})$, while subjects carry out regionally dependent cognitive tasks. In contrast to fluorodeoxyglucose PET studies that sometimes show relative hypofrontality, overall prefrontal blood flow at rest appeared normal in the schizophrenic patients whom Weinberger studied, and is only revealed as abnormal in tasks activating the DLPFC. This basic finding by now has been replicated by others (e.g., Lewis et al. 1992; Kawasaki et al. 1991; Rubin et al. 1991). As reviewed earlier, the strongest and most consistent evidence for frontal lobe involvement is for changes in DLPFC, i.e., the HASC portion of frontal lobe. Overall then, we feel that the weight of functional evidence favors abnormality of frontal HASC regions rather than of whole frontal lobe.

\section{The Limbic System}

Evidence for temporolimbic (i.e., medial temporal as distinguished from temporal neocortical) circuit involvement in schizophrenia is suggested by multiple observations. Positive symptoms of schizophrenia, including hallucinations, delusions and formal thought disorder may be associated with abnormalities in temporolimbic, as well as in the previously mentioned lateral temporal structures such as STG (Toone 1991; Trimble 1991).

Roberts (Roberts 1990, 1991), using data derived from studies of others (Van Hoesen 1982; Amaral et al. 1987; Insausti et al. 1987) and in agreement with Trimble (1991), points to the convergence of association cortical data on the entorhinal cortex and suggests a progressive loss from primary medial temporal damage in the parahippocampal gyrus (PHG) and entorhinal cortex (ERC) to pathology of association neocortex secondarily. However, Roberts' hypothesis requires that the ERC should always be most abnormal in schizophrenia - for which strong evidence is currently lacking. Another prediction, from the widespread connections of the ERC, is that most (if not all) cerebral cortex should be involved, which we argue is not the case. Our view is that the STG may form a crucial link between the limbic temporal structures emphasized by Roberts and the HASC loop. This is supported, for example, by studies such as those of Bancaud et al. (1994) suggesting that both lateral temporal neocortical and mesial limbic structures are involved in the pathophysiology of the psychotic phenomena related to temporal lobe epilepsy. Hence, we see medial temporal involve- ment in schizophrenia as a phenomenon existing alongside HASC changes, but without strong evidence to convince one that the limbic pathology is primary. We propose that indirect medial temporal involvement may be secondary to pathology in the STG and other HASC regions.

\section{Basal Ganglia}

The basal ganglia help subserve many functions noted to be abnormal in patients with schizophrenia. These include motivation, psychomotor activity and the modulation of language. The basal ganglia receive projections from numerous cortical areas, and project in multiple loops returning to cortex through the thalamus (Alexander et al. 1990).

Whether or not there are pronounced primary changes in the basal ganglia associated with the disease is still uncertain. A small number of pathologic studies have suggested pathology in the internal pallidum, (e.g., Brown et al. 1986; Bogerts et al. 1985; Bruton et al. 1990). Heckers et al. (1991) reported increased volume of striatal components in schizophrenic brains at postmortem. Studies of the basal ganglia of schizophrenic patients using MRI have yielded inconsistent findings. MRI studies of basal ganglia area (Kelsoe et al. 1988) volume and MR T1-relaxation time (Harvey et al. 1991) found no differences in schizophrenic patients. Some investigators (Jernigan et al. 1991; Swayze et al. 1992) found increased volume of the lentiform nucleus and putamen, respectively; others (Kelsoe et al. 1988) did not. Volume changes may be secondary to administration of neuroleptic medication (Chakos et al. 1994). Several glucose metabolic studies using PET have implicated basal ganglia dysfunction in schizophrenia (Early et al. 1989; Wolkin et al. 1985; Kling et al. 1986; Buchsbaum et al. 1987). Receptor PET studies estimating $B$ max values of dopamine $\mathrm{D}_{2}$ sites in drug-naive schizophrenics report inconsistent findings [see the review of Gur and Pearlson (1993)]. If there is basal ganglia involvement in schizophrenia, we suggest that it may be plausibly interpreted as secondary to primary HASC disturbances.

A recent structural MRI subtraction study emphasized thalamic alterations in schizophrenia (Andreasen et al. 1994). Because of the methods used, this study may have had reduced sensitivity for detecting neocortical differences. Changes in the thalamus, if replicated, might plausibly be attributed to secondary effects of primary lesions in cerebral cortex.

\section{DYNAMIC DISRUPTIONS IN INTERRELATIONSHIPS BETWEEN HASC AREAS}

We now discuss the functional abnormalities that follow disruptions of this network of interconnected neu- 
ral systems. The maps of systems and circuits of the type provided by Alexander and Crutcher (1990) and the high interconnectedness of HASC regions shown by Selemon and Goldman-Rakic (1988) illuminate networks that could explain and tie HASC changes conceptually to other local findings. Thus, the focus can be shifted to network disturbances rather than the pathophysiology of individual regions, especially now that the normal organizational principles of these systems are becoming better understood.

Recent Oxygen-15 PET experiments during performance of cognitive tasks in healthy controls and schizophrenic patients have helped illuminate the normal and pathophysiologic functioning of HASC circuits (e.g., Friston et al. 1991; Jonides et al. 1993; Liddle 1992). Liddle and co-workers (Liddle et al. 1992; Liddle 1992; Kibel et al. 1993) factor-analyzed patterns among schizophrenic symptoms. They found that symptoms cluster into three syndromes: (1) psychomotor poverty (flat affect, alogia, poverty of speech, decreased spontaneous movement), associated with deficits on cognitive tasks measuring the ability to plan and initiate activity, such as the Wisconsin Card Sorting Task and word generation tasks; (2) disorganization, consisting of formal thought disorder, inattention, and inappropriate affect, linked to an inability to suppress inappropriate responses on some cognitive tasks; and (3) reality distortion, contributed to by delusions and hallucinations and associated with disturbances in cognitive tasks requiring internal monitoring. A series of Oxygen $15 \mathrm{PET}$ studies (Liddle et al. 1992; Allen et al. 1993; Dolan et al. 1993; Frith et al. 1992; Liddle 1992) employing functional connectivity models (Friston et al. 1993) has helped reveal the underlying normal organizational principles of neural networks underlying various cognitive processes and how these normal patterns of functional connectivity are disrupted in schizophrenia. These investigators proposed and have later confirmed in part (Liddle et al. 1992) that the psychomotor poverty syndrome is associated with dysfunction (shown as reduced bloodflow) of the left DLPFC and left parietal cortex, the disorganization syndrome with reduced bloodflow of the right ventral prefrontal cortex and Broca's area, and the reality distortion syndrome by temporoparietal and left posterior cingulate cortical abnormalities, as well as medial temporal lobe changes (especially parahippocampal flow increases). Although several nonHASC areas were implicated in these studies, it is striking that so many portions of the HASC network were highlighted. Taken as a whole, Liddle's work argues for a dynamic imbalance in cortical (especially neocortical) neural circuits in schizophrenia, revealed as interactive functional abnormalities in a series of distributed neural circuits.

We believe that these important findings can be recast as disturbances prominently affecting the HASC, with predominant involvement of the anterior or DLPFC to IPL system corresponding to the psychomotor poverty syndrome, whereas more prominent involvement of the posterior or IPL/STG (mainly sensory) system corresponds to the reality distortion syndrome. Disconnection between anterior and posterior HASC (or possibly global involvement of the system) results in the disorganization syndrome. Thus, the relative preponderance of one clinical schizophrenia subtype or another may reflect the predominance of relative imbalance of different areas of HASC (as emphasized in Table 2) together with the subcortical and limbic areas to which they are linked.

Other examples exist of schizophrenia-related abnormalities best explained as interactive dynamic disturbances or imbalances in HASC networks. For example, abnormal function of aspects of the DLPFC-IPL-STG components of the circuit has been shown by several recent investigators. The problems in shifting of attention in schizophrenic patients (Mirsky et al. 1992) are likely mediated not only through DLPFC (Weinberger 1987; Goldman-Rakic 1990), but also through cerebral cortical structures in both the superior temporal and inferior parietal cortical regions (Mirsky et al. 1991). A similar case can be made for dynamic dysfunction in the DLPFC-IPL-hippocampal circuit (e.g., GoldmanRakic 1990) when activation by the WCST is attempted in schizophrenia.

Functional bloodflow investigations of auditory hallucinations in schizophrenic patients implicate abnormal activation of both anterior (Broca's area) and posterior (STG), portions of the heteromodal language (McGuire et al. 1993; Suzuki et al. 1993). Thus the concept of integrated HASC loops and evidence of their functional disruption in schizophrenia finds support from these studies.

\section{NEURODEVELOPMENT IN SCHIZOPHRENIA}

When do the brain abnormalities seen in patients with schizophrenia begin? The neuropathologic nature of the structural abnormalities and a lack of gliosis (Benes and Bird 1987) argue that these changes may be acquired in later fetal development or in the perinatal period (Murray and Lewis 1987; Weinberger 1987). The importance of cortical developmental disturbances in schizophrenia has been recently highlighted (Akbarian et al. 1993a,b; Bloom 1993), and their possible pathogenesis rendered more comprehensible as normal cortical developmental processes are clarified (e.g., Luskin 1993).

We hypothesize that abnormalities in HASC occur in two stages: the first stage is in the second trimester of fetal life (e.g., Bracha 1991) when deficits in cellular migration may result in such phenomena as a lack of normal asymmetry of the planum temporale, an important component of the HASC system. Neuropathologic evidence for migrational defects is increasingly convincing (e.g., Bloom 1993; Akhbarian et al. 1993a,b). 
The second stage occurs in late adolescence. It appears likely, as Flechsig proposed, that the heteromodal association cortex and its projections to hippocampus do not fully myelinate until this time (Benes and Bird 1987). Feinberg and co-workers (Feinberg 1982; Feinberg et al. 1990; Feinberg 1992) have marshaled evidence to show that brain function normally reorganizes during adolescence, a result, in part, of cortical synaptic density reductions by a process of "pruning." This process, which is most pronounced in more developed cortical regions such as HASC, results in fewer but more effective synapses that are more "functionally powerful." Accompanying the previous changes are an overall fall in cerebral metabolic rate and a reduction in cerebral functional plasticity. These changes may expose the effects of preexisting but subclinical anatomic abnormalities. Hence, the initial cortical lesion initiates a vulnerability for the later onset of clinical symptoms.

\section{A RESEARCH PROGRAM}

Clearly the linked hypotheses proposed in this study have to be judged on their heuristic value. Our group has carried out research on some of these concepts and found confirmatory evidence for them, presented earlier. We conclude with some further suggestions for future experiments.

We predict that neuropathologic surveys of cortex will reveal cortical gray matter thinning and cellular migrational abnormalities most prominently in HASC locations. MRI examination may reveal changes of HASC in subjects who are at risk for schizophrenia, either as a result of familial association or of phenotypic association (e.g., schizotypal features).

One major area of basic neurobiology that may provide information helpful to understanding schizophrenia is the study of late telencephalic development. There has been a tremendous explosion of progress recently in identifying genes that control early CNS development and development of hindbrain and caudal forebrain (Puelles and Rubenstein 1944; Tao and Lai 1992). Furthermore, progress has been made in understanding the patterns of cortical development. However, very little is known about the genetic control of development in cortical regions. The existence of the many histologically and functionally defined specialized areas of cortex (as first mapped by Brodmann) suggests that there may be genes with localized patterns of expression controlling the differentiation of these regions, and some studies have already identified genes expressed in restricted regions of cerebral cortex (Rakic 1988; CohenTannoudji 1994).

Heteromodal neocortical areas are also notable in being evolutionarily recent. Hence, schizophrenia may be thought of as a disease of the most uniquely human portions of the brain, and in fact may be a purely human disease. Thus, studies of genes whose structure or expression differ between humans and other primates may identify candidate loci for the disorder.

\section{ACKNOWLEDGMENTS}

This work was supported in part by NIMH grants MH43775 and MH43326 to Dr. Pearlson and grants from the Stanley Foundation and Scottish Rite Schizophrenia Foundation and NIMH grant MH50763 to Dr. Ross. These data were presented in part at the American College of Neuropsychopharmacology 31st Annual Meeting, San Juan, Puerto Rico, December $14-18,1992$.

\section{REFERENCES}

Akbarian S, Bunney WE Jr, Potkin SG, Wigal SB, Hagman JO, Sandman CA, Jones EG (1993a): Altered distribution of nicotinamide-adenine dinucleotide phosphate-diaphorase cells in frontal lobe of schizophrenics implies disturbances of cortical development. Arch Gen Psychiatry 50:169-177

Akbarian S, Vinuela A, Kim JJ, Potkin SG, Bunney WE Jr, Jones EG (1993b): Distorted distribution of nicotinamideadenine dinucleotide phosphate-diaphorase neurons in temporal lobe of schizophrenics implies anomalous cortical development. Arch Gen Psychiatry 50:178-187

Alexander GE, Crutcher MD (1990): Functional architecture of the basal ganglia: Neural substrates and parallel processing. Trends Neurosci 13:266-271

Allen HA, Liddle PF, Frith CD (1993): Negative features, retrieval processes and verbal fluency in schizophrenia. $\mathrm{Br}$ J Psychiatry 163:769-775

Alzheimer A (1913): Beitrage zur pathologischen anatomic der dementia praecox. Allgemeine Zeitschrift fur Psychiatric 70:810-812

Amaral DG, Insausti R, Cowan WM (1987): The entorhinal cortex of the monkey: I. Cytoarchitectonic organization. J Comp Neurol 264:326-355

Andersen RA, Bracewell RM, Barash S, Gnadt JW, Fogassi L (1990): Eye position effects on visual, memory, and saccade-related activity in areas LIP and 7a of macaque. J Neurosci 10:1176-1196

Andreasen NC, Arndt S, Swayze II V, Cizadlo T, Flaum M, O'Leary D, Ehrhardt JC, Yuh WTC (1994): Thalamic abnormalities in schizophrenia visualized through magnetic resonance image averaging. Science 266:294-297

Andreasen NC, Nasrallah HA, Dunn V, Olson SC, Grove WM, Ehrhardt JC, Coffman JA, Crossett JH(1986): Structural abnormalities in the frontal system in schizophrenia. Arch Gen Psychiatry 43:136-444

Angevine JB, Sidman RL (1961): Autoradiographic study of cell migration during histogenesis of cerebral cortex in the mouse. Nature 192:766-768

Angevine JB, Sidman RL (1962): Autoradiographic study of histogenesis in the cerebral cortex of the mouse. Anat $\operatorname{Rec} 142: 210$ 
Arnold SE, Hyman BT, Van Hoesen GW, Damasio AR (1991): Some cytoarchitectural abnormalities of the entorhinal cortex in schizophrenia. Arch Gen Psychiatry 48:625-632

Bancaud J, Brunet-Bourgin F, Chauvel P, Halgren E (1994): Anatomical origin of deja vu and vivid "memories" in human temporal lobe epilepsy. Brain 117:71-90

Barbas H, Henion TH, Dermon CR (1991): Diverse thalamic projections to the prefrontal cortex in the rhesus monkey. J Comp Neurol 313:65-94

Barbas H, Mesulam M-M (1981): Organization of afferent input to subdivisions of area 8 in the rhesus monkey. J Compr Neurol 200:407-432

Barta PE, Pearlson GD, Powers RE, Richards SS, Tune LE (1990): Reduced superior temporal gyrus volume in schizophrenia: Relationship to hallucinations. Am J Psychiatry $147: 1457-1462$

Barta PE, Petty RG, K.McGilchrist I, Lewis RW, Casanova RE, Powers RE, Brill LB, Pearlson GD (1995): Asymmetry of the planum temporale: Methodologic considerations and clinical associations. Psychiatry Res (in press)

Benes F (1989): Myelination of cortical-hippocampal relays during adolescence. Schizophr Bull 15:585-593

Benes FM, Davidson J, Bird ED (1986): Quantitative cytoarchitectural studies of the cerebral cortex of schizophrenics. Arch Gen Psychiatry 43:31-35

Benevento LA, Fallon J, Davis BJ, Rezak M (1977): Auditoryvisual interaction in single cells in cortex of the superior temporal sulcus and the orbital frontal cortex of the macaque monkey. Exp Neurol 57:849-872

Benson DF, Geschwind N (1968): Cerebral dominance and its disturbances. Pediatr Clin North Am 15:759-769

Berman KF, Torrey EF, Daniel DG, Weinberger DR (1992); Regional cerebral blood flow in monozygotic twins discordant and concordant for schizophrenia. Arch Gen Psychiatry 49:927-934

Berman KF, Weinberger DR (1990): The prefrontal cortex in schizophrenia and other neuropsychiatric diseases: In vivo physiological correlates of cognitive deficits. Prog Brain Res 85:521-537

Berman KF, Weinberger DR (1994): Lateralization of cortical function during cognitive tasks: Regional cerebral blood flow studies of normal individuals and patients with schizophrenia. J Neurol Neurosurg Psychiatry 53:150-160

Berry M, Rogers AW (1965): The migration of neuroblasts in the developing cerebral cortex. J Anat 99:691-709

Bignall KE, Imbert M (1969): Polysensory and cortico-cortical projections to frontal lobe of squirrel and rhesus monkeys. Electroencephalogr and Clin Neurophysiol 26: 206-215

Bloom FE (1993): Advancing a neurodevelopmental origin for schizophrenia. Arch Gen Psychiatry 50:224-227

Bogerts B, Ashtari M, Degreff G, Alvir JM, Bilder RM, Lieberman JA (1990): Reduced temporal limbic structure volumes on magnetic resonance images in first episode schizophrenia. Psychiatry Res 35:1-13

Bogerts B, Meertz E, Schoenfeld-Bausch R (1985): Basal ganglia and limbic system pathology in schizophrenia: a morphometric study. Arch Gen Psychiatry 42:784-691

Borod JD, Koff E, Perlman LM, Nicholas M (1986): The rela- tionship between emotional facial expression and nonemotional facial movement in patients with focal brain damage. J Clin Exp Neuropsychol 8:137-144

Bracha HS (1991): Etiology of structural asymmetry in schizophrenia: an alternative hypothesis [letter]. Schizophr Bull 17:551-553

Breier A, Buchanan RW, Elkashef A, Munson RC, Kirkpatrick B, Gellad F (1992): Brain morphology and schizophrenia. A magnetic resonance imaging study of limbic, prefrontal cortex, and caudate structures. Arch Gen Psychiatry 49:921-926

Brown R, Colter N, Corsellis JAN, Crow TJ, Frith CD, Jagoe R, Johnstone EC, Marsh L (1986): Postmortem evidence of structural brain changes in schizophrenia: Differences in brain weight, temporal horn area, and parahippocampal gyrus compared with affective disorder. Arch Gen Psychiatry 43:36-42

Bruce C, Desimone R, Gross CG (1981): Visual properties of neurons in a polysensory area in superior temporal sulcus of the macaque. J Neurophysiol 46:369-384

Bruton CJ, Crow TJ, Frith CD, Johnstone EC, Owens DG, Roberts GW (1990): Schizophrenia and the brain: A prospective cliniconeuropathological study. Psychol Med. 20:285-304

Buchsbaum MS (1990): The frontal lobes, basal ganglia, and temporal lobes as sites for schizophrenia. [Review]. Schizophr Bull 16:379-389

Buchsbaum MS, Haier RJ, Potkin SG, Nuechterlein K, Bracha HS, Katz M, Lohr J, Wu J, Lottenberg S, Jerabek PA (1992): Frontostriatal disorder of cerebral metabolism, in never-medicated schizophrenics. Arch Gen Psychiatry 49:935-942

Buchsbaum MS, Ingvar DH, Kessler R (1987): Cerebral glucography with positron emission tomography. Arch Gen Psychiatry 39:251-259

Casanova MF, Goldberg TE, Suddath RL, Daniel DG, Rawlings R, Lloyd DG, Loats HL, Kleinman JE, Weinberger DR (1990): Quantitative shape analysis of the temporal and prefrontal lobes of schizophrenic patients: A magnetic resonance image study. J Neuropsych Clin Neurosci $2: 363-372$

Chakos MH, Lieberman JA, Bilder RM, Ashtari M (1994): Increase in caudate nuclei volumes of frrst-episode schizophrenic patients taking antipsychotic drugs. Am J Psychiatry 151:1430-1436

Chavis DA, Pandya DN (1976): Further observation on corticofrontal connections in the rhesus monkey. Brain Res $117: 369-386$

Chi JG, Dooling EC, Giles FH (1977): Gyral development of the human brain. Ann Neurol 1:86-93

Cleghorn JM, Garnett ES, Nahmias C, Firnau G, Brown GM, Kaplan R, Szechtman H, Szechtman B (1989): Increased frontal and reduced parietal glucose metabolism in acute untreated schizophrenia. Psychiatry Res 28:119-133

Cleghorn JM, Kaplan RD, Nahmias C, Garnett ES, Szechtman H, Szechtman B (1989): Inferior parietal region implicated in neurocognitive impairment in schizophrenia [letter; comment]. Arch Gen Psychiatry 46:758-760

Cohen-Tannoudji M, Babinet C, Wassef M (1994): Early determination of a mouse somatosensory cortex marker. Nature 368:460 
Crow TJ (1990a): Strategies for biological research: Psychosis as an anomaly of the cerebral dominance gene. In $\mathrm{H} \mathrm{Haf-}$ ner, WF Gattaz, (eds), Search for the Causes of Schizophrenia. Berlin, Springer-Verlag, pp. 383-396

Crow TJ (1990b): Temporal lobe asymmetries as the key to the etiology of schizophrenia. Schizophr Bull 16:433-443

David AS (1990): Insight and psychosis [review]. Br J Psychiatry 156:798-808

DeLisi LE, Hoff AL, Schwartz JE, Shields GW, Halthore SN, Gupta SM, Henn FA, Anand AK (1991): Brain morphology in first-episode schizophrenic-like psychotic patients: A quantitative magnetic resonance imaging study. Biol Psychiatry 29:159-175

Deuel RK, Dunlop NL (1980): Hand preferences in the rhesus monkey. Implications for the study of cerebral dominance. Arch Neurol 37:217-221

Dolan RJ, Bench CJ, Liddle PF, Friston KJ, Frith CD (1993): Dorsolateral prefrontal cortex dysfunction in the major psychoses; symptom or disease specificity? J Neurol Psychiatry $56: 1,290-1,294$

Droogleever-Fortuyn J (1979): On the neurology of perception. Clin Neurol Neurosurg 81:97-107

Early TS, Reiman EM, Raichle ME, Spitznagel EL (1989): Left globus pallidus abnormality in never-medicated patients with schizophrenia. Proc Nat Acad Sci 84:561-563

Eidelberg D, Galaburda AM (1984): Inferior parietal lobule. Divergent architecture asymmetries in the human brain. Arch Neurol 41:843-852

Falkai P, Bogerts B, Benno G, Greve B, Pfeiffer U, Machus B, Folsch-Reetz B, Majtenyi C, Ovary I (1992): Loss of sylvian fissure asymmetry in schizophrenia: A quantitative post-mortem study. Schizophr Res 17:23-32

Feinberg I (1982): Schizophrenia: caused by a fault in programmed synaptic elimination during adolescence? J Psychiatry Res 17:319-334

Feinberg I (1992): Neurodevelopmental model of schizophrenia [letter; comment]. Biol Psychiatry 32:212-213

Feinberg I, Thode HC, Jr., Chugani HT, March JD (1990): Gamma distribution model describes maturational curves for delta wave amplitude, cortical metabolic rate, and synaptic density. J Theor Biol 142:149-161

Flaum MA, Swayze VW, Gupta S, O'Leary DS, Andreasen NC (1992): Symptom domains and neural substrates of schizophrenia: An MRI study. ACNP New Research Abstracts (abst.)

Flechsig P (1896): Die Lokalisation der Geistigen Vorgange Insbesobdere der Sinnesempfindungen des Menschen. Leipzig, Verlag von Veit

Flor-Henry P (1969): Psychosis and temporal lobe epilepsy. A controlled investigation. Epliepsia 10:363-395

Friston KJ, Frith CD, Liddle PF, Frackowiak RS (1991): Investigating a network model of word generation with positron emission tomography. Proceedings of the Royal Society of London-Series B: Biol Sciences 244(1310): 101-106

Friston KJ, Frith CD, Liddle PF, Frackowiak RS (1993): Functional connectivity: The principal-component analysis of larte (PET) data sets. J Cereb Blood Flow Metab 13:5-14

Frith CD, Friston KJ, Liddle PF, Frackowiak RSJ (1991): Willed action and the prefrontal cortex in man: A study with PET. Proc Roy Soc London, Series B 244:241-246

Frith CD, Friston KJ, Liddle PF, Frackowiak RS (1992): PET imaging and cognition in schizophrenia. J Royal Soc Med $85: 222-224$

Galaburda A, Sanides F (1980): Cytoarchitectonic organization of the human auditory cortex. J Comp Neurol 190:597-610

Geschwind N (1965): Disconnection syndromes in animals and man. Brain 88:237-294

Geschwind N (1972): Cerebral dominance and anatomic asymmetry. N Engl J Med 287:194-195

Geschwind N, Levitsky W (1968): Human brain: Left-right asymmetries in temporal speech region. Science 161: 186-187

Gloor P (1990): Experimental phenomena of temporal lobe epilepsy: Facts and hypotheses [review]. Brain 113: 1673-1694

Goldman-Rakic PS (1987): Section I: The nervous system. Vol. V: Higher functions of the brain. In F Plum, VB Mountcastle, SR Geiger (eds) The Handbook of Physiology. Bethesda, Maryland, American Physiologic Society, pp. 373-417

Goldman-Rakic PS (1990): Cellular and circuit basis of working memory in prefrontal cortex of nonhuman primates. In HBM Uylings, CG Van Eden, JPC De Bruin, MA Corner, MGP Feensta (eds), Progress in Brain Research. New York, Elsevier

Goldman-Rakic PS (1991): Prefrontal cortical dysfunction in schizophrenia: The relevance of working memory. In BJ Carroll, JE Barret (eds), Psychopathology and the Brain. New York: Raven, pp. 1-23

Guillery RW (1959): Afferent fibers to the dorsomedial thalamic nucleus in the cat. J Anat 93:403-419

Gur R, Pearlson GD (1993): Neuroimaging in schizophrenia. Schizophr Bull 19:337-354

Gur RE, Resnick SM, Gur RC, Alavi A, Caroff S, Kushner M, Reivich M (1987): Regional brain function in schizophrenia. II. Repeated evaluation with positron emission tomography. Arch Gen Psychiatry 44:126-129

Hanaway J, Lee SI, Netsky MG (1968): Pachygyria: Relation of findings to modern embryologic concepts. Neurology 18:791-799

Harrington A, Oepen G, Spitzer M (1989): Disordered recognition and perception of human faces in acute schizophrenia and experimental psychosis. Comp Psychiatry 30:376-384

Harvey I, Ron MA, Murray R, Lewis S, Barker G, McManus D (1991): MRI in schizophrenia: Basal ganglia and white matter T1 time. Psychol Med 21:587-590

Heckers S, Heinsen H, Heinsen Y, Beckmann H (1991): Cortex, white matter, and basal ganglia in schizophrenia: A volumetric postmortem study. Biol Psychiatry 29: 556-566

Heilman KM, Watson RT, Valenstein (1993): Localization in Neuropsychology. New York, Academic Books

Hill WCO (1972): Evolutionary Biology of the Primates. London, Academic Press 
Hofer HO (1969): On the evolution of the craniocerebral topography in primates. Ann NY Acad Sci 162:15-24

Hyvarinen J (1981): Regional distribution of functions in parietal association area 7 of the monkey. Brain Res 206:287-303

Insausti R, Amaral DG, Cowan WM (1987): The entorhinal cortex of the monkey: I. Cortical afferents. J Comp Neurol 264:356-395

Insausti R, Armaral DG, Cowan WM (1987): The entorhinal cortex of the monkey: II. Subcortical efferents. J Comp Neurol 264:396-408

Jacobson S and Trojanowski JQ (1975): Corticothalamic neurons and thalamocortical terminal fields: an investigation in rat using horseradish peroxidase and autoradiography. Brain Res 85:385-401

Jakob AL, Beckmann H (1989): Gross anatomic and histologic criteria for developmental disorders in the brains of schizophrenics. J Royal Soc Med 82:468

Jerison HJ (1973): Evolution of the Brain and Intelligence. New York, Academic Press

Jernigan TL, Zisook S, Heaton RK, Moranville JT, Hesselink JR, Braff DL (1991): Magnetic resonance imaging abnormalities in lenticular nuclei and cerebral cortex in schizophrenia. Arch Gen Psychiatry 48:881-890

Jibiki I, Maeda T, Kubota T, Yamaguchi N (1993): 1231-IMP SPECT brain imaging in epileptic psychosis: A study of two cases of temporal lobe epilepsy with schizophrenialike syndrome. Neuropsychobiology 28:207-211

Jones EG, Powell TPS (1970): An anatomic study of converging sensory pathways within the cerebral cortex of the monkey. Brain 93:793-820

Jonides J, Smith EE, Koeppe RA, Awh E, Minoshima S, Mintun MA (1993): Spatial working memory in humans as revealed by PET. Nature 363:623-625

Kawasaki Y, Maeda Y, Suzuki M (1991): SPECT analysis of rCBF changes during Wisconsin Card Sorting Test. Biol Psychiatry 29:333S

Kelsoe JR, Cadet JL, Pickar D, Weinbergre DR (1988): Quantitative neuroanatomy in schizophrenia. A controlled magnetic resonance imaging study. Arch Gen Psychiatry 45:533-541

Kibel DA, Laffont I, Liddle PF (1993): The composition of the negative syndrome of chronic schizophrenia. Br J Psychiatry 162:744-750

Kievit J, Kuypers HGJM (1975): Basal forebrain and hypothalamic connections to frontal and parietal cortex in the rhesus monkey. Science 187:660-662

Kishimoto H, Kuwahara H, Ohno S, Takazu O, Hama Y, Sato C, Ishii T, Nomura Y, Fujita H, Miryauchi T (1987): Three subtypes of chronic schizophrenia identified, using 11C. glucose positron emission tomography. Psychiatry Res 21:285-292

Kling AS, Metter EJ, Riege WH, Kuhl DE (1986): Comparison of PET measurement of local brain glucose metabolism and CAT measurement of brain atrophy in chronic schizophrenia and depression. Am J Psychiatry 143: $175-180$

Kluver H (1951): Functional differences between the occipital and temporal lobes. In LA Jeffress (ed), Cerebral Mechanisms in Behavior. New York, Wiley, pp. 147-199
Knight RA, Sims-Knight JE (1987): Differential effects of parietal or temporoparietal lesions on human N200 and P300. Neuroscience 22 (suppl.):S521

Kojima S (1980): Prefrontal unit activity in the monkey: Relation to visual stimuli and movements. Exp Neurol 69:110-123

Kojima S, Matsumura M, Kubota K (1981): Prefrontal neuron activity during delayed-response performance without imperative GO signals in the monkey. Exp Neurol 74:396-407

Kubota K, Tonoike M, Mikami A (1980): Neuronal activity in the monkey dorsolateral prefrontal cortex during a discrimination task with delay. Brain Res 183:29-42

Kulynych JJ, Vladar K, Jones DW, Weinberger DR (1993): Three-dimensional surface rendering in MRI morphometry: A study of the planum temporale. J Comp Assist Tomogr 17:529-535

Lewine RRJ (1981): Sex differences in schizophrenia. Timing or subtypes? Psychol Bull 90:432-434

Lewis SW, Ford RA, Syed GM, Reveley AM, Toone BK (1992): A controlled study of $99 \mathrm{mTc}$-HMPAO single photon emission imaging in chronic schizophrenia. Psychol Med 22:27-35

Liddle PF AU-Friston KJ, Frith CD, Hirsch SR, Jones T, Frackowiak RSJ (1992): Patterns of cerebral blood flow in schizophrenia. Br J Psychiatry 160:179-186

Liddle PF (1992): PET scanning and schizophrenia-what progress? Psychol Med 22:557-560

Luskin MB (1993): Mammalian forebrain development: How cells find a permanent home and establish their identity. J NIH Res 5:60-64

Lynch JC (1980): The functional organization of the posterior parietal association cortex. Behav Brain Sci 3:485-499

McCarley RW, Shenton ME, O'Donnell BF, Kikinis R, Nestor PG, Jolesz FA (1993): Auditory P300 abnormalities and left posterior temporal gyrus volume reduction in schizophrenia. Arch Gen Psychiatry 50:190-197

McGilchrist I (1993): Inferior parietal gray matter loss in schizophrenia. 146th Annual Meeting of the American Psychiatric Association, San Francisco, New Research Abstract 230:117(abst.)

McGuire PK, Shah GM, Murray RM (1993): Increased blood flow in Broca's area during auditory hallucinations in schizophrenia. Lancet 342:703-706

Manschreck TC, Ames D (1984): Neurologic features and psychopathology in schizophrenic disorders. Biol Psychiatry 19:703-719

Menon RR, Barta PE, Aylward EH, Richards SS, Vaughn DD, Tien AY, Harris Gj, Pearlson GD (1995): Posterior superior temporal gyrus in schizophrenia: grey matter changes and clinical correlates. Schizoph Res (in press)

Mesulam M-M (1985): Principles of Behavioral Neurology. Philadelphia, FA Davis

Mesulam M-M (1981): A cortical network for directed attention and unilateral neglect. Ann Neurol 10:309-325

Mesulam M-M, Mufson EJ (1984): Neural inputs into the nucleus basalis of the substantia innominata in the rhesus monkey. Brain 107:253-274

Mesulam M-M, Van Hoesen GW, Pandya DN, Geschwind 
$N$ (1977): Limbic and sensory connections of the inferior parietal lobule (Area PG) in the rhesus monkey: A study with a new method for horseradish peroxidase histochemistry. Brain Res 136:393-414

Mesulam M-M (1990): Large-scale neurocognitive networks and distributed processing for attention, language and memory. Ann Neurol 28:597-613

Mesulam M-M, Geschwind N (1983): On the possible role of neocortex and its limbic connections in the process of attention and schizophrenia. J Psychiatr Res 14:249-261

Mirsky AF, Anthony BJ, Duncan CC, Ahearn MB, Kellam SG (1991): Analysis of the elements of attention: A neural psychological approach. Neuropsychol Rev 2:109-145

Mirsky AF, Lochhead SJ, Jones BP, Kugelmass S, Walsh D, Kendler KS (1992): On familial factors in the attentional deficit in schizophrenia: A review and report of two new subject samples. J Psychiatr Research 26:383-403

Morecraft RJ, Geula C, Mesulam M-M (1992): Cytoarchitecture and neural afferents of orbitofrontal cortex in the brain of the monkey. J Comp Neurol 323:341-358

Murray RM, Lewis SR (1987): Is schizophrenia a developmental disorder? Br Med J 295:681-682

Musalek M, Podreka I, Walter H, Suess E, Passweg V, Nutzinger D, Strobl R, Lesch OM (1989): Regional brain function in hallucinations: A study of regional cerebral blood flow with $99 \mathrm{mTc}$-HMPAO SPECT in patients with auditory hallucinations, tactile hallucinations and normal controls. Comp Psychiatry 30:99-108

Nottebohm F, Stokes TM, Leonard CM (1976): Central control of song in the canary. J Comp Neurol 165:457-486

Pandya DN, Kuypers HGJM (1969): Corticocortical connections in the rhesus monkey. Brain Res 13:13-36

Pandya DN, Van Hoesen GW, Mesulam M-M (1981): Efferent connections of the cingulate gyrus in the rhesus monkey. Exp Brain Res 42:319-330

Park S, Holzman PS (1992): Schizophrenics show spatial working memory deficits. Arch Gen Psychiatry 49:975982

Pearlson GD (1991): PET scans in schizophrenia: What have we learned? Ann Clin Psychiatry 3:97-101

Pearlson GD, Marsh L (1993): MRI in Psychiatry. In Oldham JM, Reba M (eds), American Psychiatric Assocn. 12th Annual Review, Washington DC, APA Press, pp. 347-382

Penfield W, Perot P (1963): The brain's record of auditory and visual experience. Brain 86:595-696

Peterson SE, Robinson DL, Currie JN (1989): Influences of lesions of parietal cortex on visual spatial attention in humans. Exp Brain Res 76:267-280

Petrides M, Pandya DN (1984): Projections to the frontal cortex from the posterior parietal region in the rhesus monkey. J Comp Neurol 228:105-116

Petty RG, Barta PE, Pearlson GD, McGilchrist IK, Lewis RW, Tien AY, Pulver A, Vaughn DD, Casanova MF, Powers RE (1995): Reversal of asymmetry of the planum temporale in schizophrenia suggests neurodevelopmental etiology. Am J Psychiatry 152:715-721.

Posner MI, Early TS, Reiman E, Pardo P, Dhawan M (1988): Asymmetries in hemispheric control of attention in schizophrenia. Arch Gen Psychiatry 45:814-821
Puelles L, and Rubenstein JLR (1993): Expression patterns of homeobox and other putative regulatory genes in the embryonic mouse forebrain suggest a neuromeric organization. Trends Neurosci 16:472-479

Rajkowska G, Goldman-Rakic PS (1991): Cytoarchitectonic remapping of areas 9 and 46 in the human prefrontal cortex by quantitative criteria. International Congress on Schizophrenia Research (abst.)

Rakic P (1988): Specifications of cerebral cortical areas. Science 241:170-176

Reite M, Teale P, Goldstein L, Whalan J, Linnville S (1989): Late auditory magnetic sources may differ in the left hemisphere of schizophrenic patients. Arch Gen Psychiatry 46:565-572

Roberts GW (1990): Schizophrenia: The cellular biology of a functional psychosis. Trends Neurosci 13:207-211

Roberts GW (1991): Schizophrenia: A neuropathologic perspective. Br J Psychiatry 158:8-17

Rosene DL, Van Hoesen GW (1977): Hippocampal efferents reach widespread areas of cerebral cortex and amygdala in the rhesus monkey. Science 198:315-317

Rossi A, Strattar P, Mattei P, Cupillari M, Bozzao A, Gallucci M, Casacchia M (1994): Planum temporale in schizophrenia: A magnetic resonance imaging study. Schizophr Res 7:19-22

Rubin P, Holm S, Friberg L, Videbech P, Andersen HS, Bendsen BB, Stromso N, Larsen JK, Lassen NA, Hemming. sen R (1991): Altered modulation of prefrontal and subcortical brain activity in newly diagnosed schizophrenia and schizophreniform disorder: A regional cerebral blood flow study. Arch Gen Psychiatry 48:987-995

Sarnat HB, Netsky MG (1981): Evolution of the Nervous System. New York, Oxford University Press

Schlaepfer TE, Harris GJ, Aylward EH, McArthur JC, Peng LW, Lee S, Pearlson GD (1995): Structural difference in the cerebral cortex of normal male and female subjects. Psychiatry Res Neuroimaging (in press)

Schlaepfer TE, Harris GJ, Tien AY, Federman EB, Peng LW, Lee S, Pearlson GD (1994): Pattern of decreased regional cortical gray matter volume using magnetic resonance imaging in schizophrenia. Am J Psychiatry 151:842-848

Schmahmann JD and Pandya DN (1990): Anatomic investigation of projections from thalamus to posterior parietal cortex in the rhesus monkey: A WGA-HRP and fluorescent tracer study. J Comp Neurol 295:299-326

Selemon LD, Goldman-Rakic PS (1988): Common cortical and subcortical targets of the dorsolateral prefrontal and posterior parietal cortices in the rhesus monkey: Evidence for a distributed neural network subserving spatially guided behavior. J Neurosci 8:4049-4068

Seltzer B, Pandya DN (1978): Afferent cortical connections and architectonics of the superior temporal sulcus and surrounding cortex in the rhesus monkey. Brain Res 149:1-24

Seltzer B, Pandya DN (1984): Further observations of parietotemporal connections in the rhesus monkey. Exp Brain Res 55:301-312

Shenton ME, Kikinis R, Jolesz FA, Pollak SD, LeMay M, Wible CG, Hokama H, Martin J, Metcalf D, Coleman M, McCarley RW (1992): Abnormalities of the left temporal 
lobe and thought disorder in schizophrenia: A quantitative magnetic resonance imaging study. N Engl J Med 327:604-612

Shenton ME, Kikinis R, Wible CG, Hokama H, Jolesz FA, McCartley RW (1993): Alterations in left temporal and temporal lobe gyral patterns in schizophrenia. Biol Psychiatry $33: 123 \mathrm{~A}$

Sidman RL, Angevine JB (1962): Autoradiographic analysis of time of origin of nuclear versus cortical components of mouse telencephalon. Anat Rec 142:326-327

Southard EE (1915): On the topographical distribution of cortex lesions and anomalies in dementia praecox with some account of their functional significance. Am J Insanity 71:603-671

Steinmetz H, Rademacher J, Huang Y, Hefter H, Zilles K, Thron A, Treund HJ (1989): Cerebral asymmetry: MR planimetry of the human planum temporale. J Comput Asst Tomogr 13:996-1005

Steinmetz H, Rademacher J, Jancke L, Huang YX, Thron A, Zilles K (1990): Total surface of temporoparietal intrasylvian cortex: Diverging left-right asymmetries. Brain Lange 39:357-372

Stevens JR (1991): Psychosis and the temporal lobe. In D Smith, D Treiman, M Trimble (eds), New York, Raven, Advances in Neurology. pp. 79-96

Suzuki M, Yuasa S, Minabe Y, Murata M, Kurchi M (1993): Left superior temporal blood flow increases in schizophrenic and schizophreniform patients with auditory hallucinations: A longitudinal case study using 1231-IMP SPECT. Euro Arch Psychiatry Clin Neurosci 242:257-261

Swayze VW, Andreasen NC, Alliger RJ, Yuh WTC, Ehrhardt JC (1992): Subcortical and temporal structures in affective disorder and schizophrenia: A magnetic resonance imaging study. Biol Psychiatry 31:221-240

Tamminga CA, Thaker GK, Buchanan R, Kirkpatrick B, Alphs LD, Chase TN, Carpenter WT (1992): Limbic system abnormalities identified in schizophrenia using positron emission tomography with fluorodeoxyglucose and neocortical alterations with deficit syndrome. Arch Gen Psychiatry 49:522-539

Tao W, Lai E (1992): Telencephalon-restricted expression of BF-1, a new member of the HNF-3/fork head gene family, in the developing rat brain. Neuron 8:957-966

Thaker GK, Nguyen JA, Tamminga CA (1989): Saccadic distractibility in schizophrenic patients with tardive dyskinesia. Arch Gen Psychiatry 46:755-756
Toone BK (1991): The psychoses of epilepsy. J R Society Med 46:457-459

Trimble MR (1991): The limbic system and related anatomic connections. In New York, Raven, The Psychoses of Epilepsy.

Trojanowski JQ, Jacobson S (1976): Areal and laminar distribution of some pulvinar cortical efferents in rhesus monkey. J Comp Neurol 169:371-392

Van Hoesen GW (1982): The parahippocampal gyrus: Its cortical connections in the monkey. Trends Neurosci $5: 345-350$

Viliger E (1931): Brain and Spinal Cord. Philadelphia, J.B. Lippincott, 136-137

von Bonin G, Bailey P (1947): The Neocortex of Macaca Mulatta. Urbana, IL, University of Illinois Press

Weinberger DR (1987): Implications of normal brain development for the pathogenesis of schizophrenia. Arch Gen Psychiatry 44:660-669

Weinberger DR (1991): Hippocampal injury and chronic schizophrenia. Biol Psychiatry 29:508-517

Weinberger DR, Berman KF, Suddath R, Torrey EF (1992): Evidence of dysfunction of prefrontal-limbic network in schizophrenia: A magnetic resonance imaging and regional cerebral blood flow of discordant monozygotic twins. Am J Psychiatry 149:890-897

Wiesel FA, Wik G, Sjogren I, Blomquist G, Greitz T, StoneElander S (1987): Regional brain glucose metabolism in drugfree schizophrenic patients and clinical correlates. Acta Psychiatrica Scandinavica 76:628-641

Wolkin A, Jaeger J, Brodie JD, Wolf AP, Fowler J, Rotrosen H, Gomez-Mont F, Cancro R (1985): Persistence of cerebral metabolic abnormalities in chronic schizophrenia as determined by positron emission tomography. Am J Psychiatry 142:564-571

Wood FB, Flowers DL (1990): Hypofrontal vs hyposylvian blood flow in schizophrenia. Schizophr Bull 16:413-424

Yeterian EH and Pandya DN (1991): Corticothalamic connections of the superior sulcus in rhesus monkeys. Exp Brain Res 83:268-84

Zec RF, Weinberger DR (1986): Handbook of Schizophrenia, Vol 1: The Neurology of Schizophrenia. New York, Elsevier

Zipursky R, Lim KO, Sullivan EV, Byron WB, Pfefferbaum A (1992): Widespread cerebral gray matter volume deficits in schizophrenia. Arch Gen Psychiatry 49:195-205 